\title{
Considerations regarding the inspection of equipment designed for use in potentially explosive atmospheres
}

\author{
Lucian Moldovan ${ }^{1 *}$, Mihai Magyari ${ }^{1}$, Marcel $\operatorname{Rad}^{1}$, Clementina Moldovan ${ }^{2}$ and Sorin \\ Zsido $^{1}$ \\ ${ }^{1}$ INCD INSEMEX, Department for Safety of Explosionproof Equipment and Installations, 32-34 \\ G-ral Vasile Milea street, Petrosani, Romania \\ ${ }^{2}$ University of Petrosani, Department of Environmental Engineering and Geology, 20 University \\ street, Petrosani, Romania
}

\begin{abstract}
The special characteristics providing protection to explosion for equipment design for use in potentially explosive atmospheres must be preserved during their entire period of use. Thus, the equipment designed for use in potentially explosive atmosphere shall be subjected to specific inspections in order to verify that the characteristics on which explosion protection is based were not depreciated in time. The purpose of the paper is to underline the importance of inspections in case of equipment intended to be used in potentially explosive atmospheres and to provide specific recommendations in this matter.
\end{abstract}

\section{Introduction}

Electrical equipment and installations operating in potentially explosive atmospheres have specific features to make them suitable to operate in such areas. Specific features on which explosion protection is based must be preserved on entire life of such installations [1]. Equipment operating in explosive atmospheres shall be according the ATEX Directive [2].

Even if equipment has a correct functional operation, this doesn't mean that the integrity of the special characteristics on which explosion protection depends is preserved [3].

In case of inspections applied for older installations, it is recommended to be carried out according to the standards in effect at the date of the installation [1].

The inspection represents an action comprising careful examination of an item (equipment) carried out either without dismantling, or with the addition of partial dismantling (as required), supplemented by means such as measurement, in order to arrive at a reliable conclusion regarding the condition of an item (equipment) $[1,4]$.

Inspections are classified according their grade and type [1].

The classification of inspections according their grade is as follows [1]:

* Corresponding author: lucian.moldovan@insemex.ro 
- Visual inspection - inspection which identifies, those defects apparent to the eye that can be highlighted without the use of access equipment or tools (for example missing bolts);

- Close inspection - inspection which includes the aspects covered by a visual inspection and, in addition, identifies those defects which will be apparent only by the use of access equipment (for example loose bolts);

- Detailed inspection - inspection which includes those aspects covered by a close inspection and, in addition, identifies those defects which can only be noticed by opening the enclosure, and/or using, where necessary, tools and test equipment (fotr example loose terminations).

According to the type of inspection, these are classified as follows [1]:

- Initial inspections - these are used to check that the selected type of protection and its installation are appropriate [1]. The initial inspections are based on detailed inspections and the requirements are covered in the standard SR EN 60079-14 [5].

- Periodic inspections - these may be visual, close or detailed. Periodic inspections are performed at specific time intervals according to an inspection program [1].

- Sample inspections - these may be visual, close or detailed. The size and composition of all samples shall be determined with regard to the purpose of the inspection. Sample inspections should not be expected to reveal faults of a random nature, such as loose connections, but should be used to monitor the effects of environmental conditions, vibration, inherent design weakness, etc. [1].

Another concept for the types of inspection is represented by continuous supervision, which uses the visual or close inspections. Where the installation falls outside the capability for continuous supervision it shall be subject to periodic inspection [1].

The results of all inspections shall be recorded and retained, and may indicate the need for further actions (maintenance or repair).

\section{Specific requirements for inspections}

The installation of an equipment must be made in accordance with its technical documentation $[1,3,4,5,6,8,9]$. Before the commissioning of an installation or equipment, an initial inspection must be performed and the results shall be recorded and retained [1]. As part of the plant commissioning and start up procedures, initial inspection and other additional requirements are provided in the specific standard SR EN 60079-14 [5]. The initial inspection must be performed with a detailed grade in order to check that all applicable aspects regarding the characteristics providing protection to explosion. The aspects to be checked during inspections are also related to the type(s) of protection involved in the construction of the equipment. The operations to be performed in relation to the type of inspection are detailed in the Table 1 below, for the types of protection flameproof enclosure " $d$ ", increased safety "e", non-incendive " $n$ " and protection by enclosures " $t$ ".

Table 1. Operations to be performed during inspections (for "d", "e", " $n$ " and " $t$ ") [1]

\begin{tabular}{|c|c|c|c|c|c|c|c|c|c|c|}
\hline \multirow{3}{*}{\multicolumn{2}{|c|}{ Check that: }} & \multicolumn{3}{|c|}{ Ex “d" } & \multicolumn{3}{|c|}{ Ex "e" } & \multicolumn{3}{|c|}{$\begin{array}{l}\text { Ex"n" } \\
\text { Ex"t" }\end{array}$} \\
\hline & & \multicolumn{9}{|c|}{ Grade of inspection: } \\
\hline & & D & $\mathbf{C}$ & $\mathbf{V}$ & $\mathbf{D}$ & $\mathbf{C}$ & $\mathbf{V}$ & $\mathbf{D}$ & $\mathbf{C}$ & $\mathbf{V}$ \\
\hline A & GENERAL (ALL EQUIPMENT) & & & & & & & & & \\
\hline 1 & $\begin{array}{l}\text { Equipment is appropriate to the EPL/zone requirements } \\
\text { of the location }\end{array}$ & $\mathrm{X}$ & $\mathrm{X}$ & $\bar{X}$ & $\mathrm{X}$ & $\mathrm{X}$ & $\mathrm{X}$ & $\mathrm{X}$ & $\mathrm{X}$ & $\mathrm{X}$ \\
\hline 2 & Equipment group is correct & $\mathrm{X}$ & $\mathrm{X}$ & & $\mathrm{X}$ & $\mathrm{X}$ & & $\mathrm{X}$ & $\mathrm{X}$ & \\
\hline 3 & Equipment temperature class is correct (only for gas) & $\mathrm{X}$ & $\mathrm{X}$ & & $\mathrm{X}$ & $\mathrm{X}$ & & $\mathrm{n}$ & $\mathrm{n}$ & \\
\hline
\end{tabular}




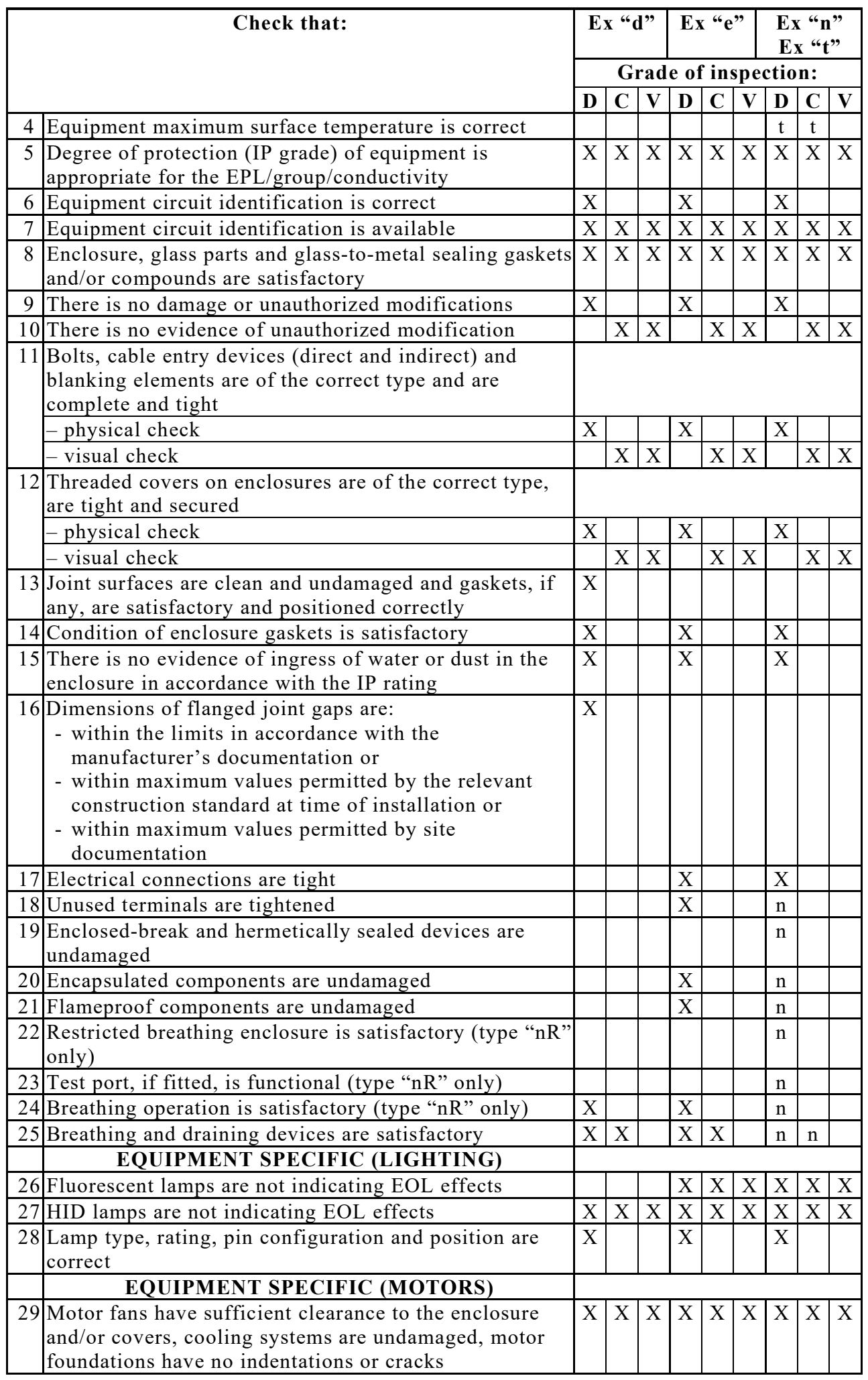




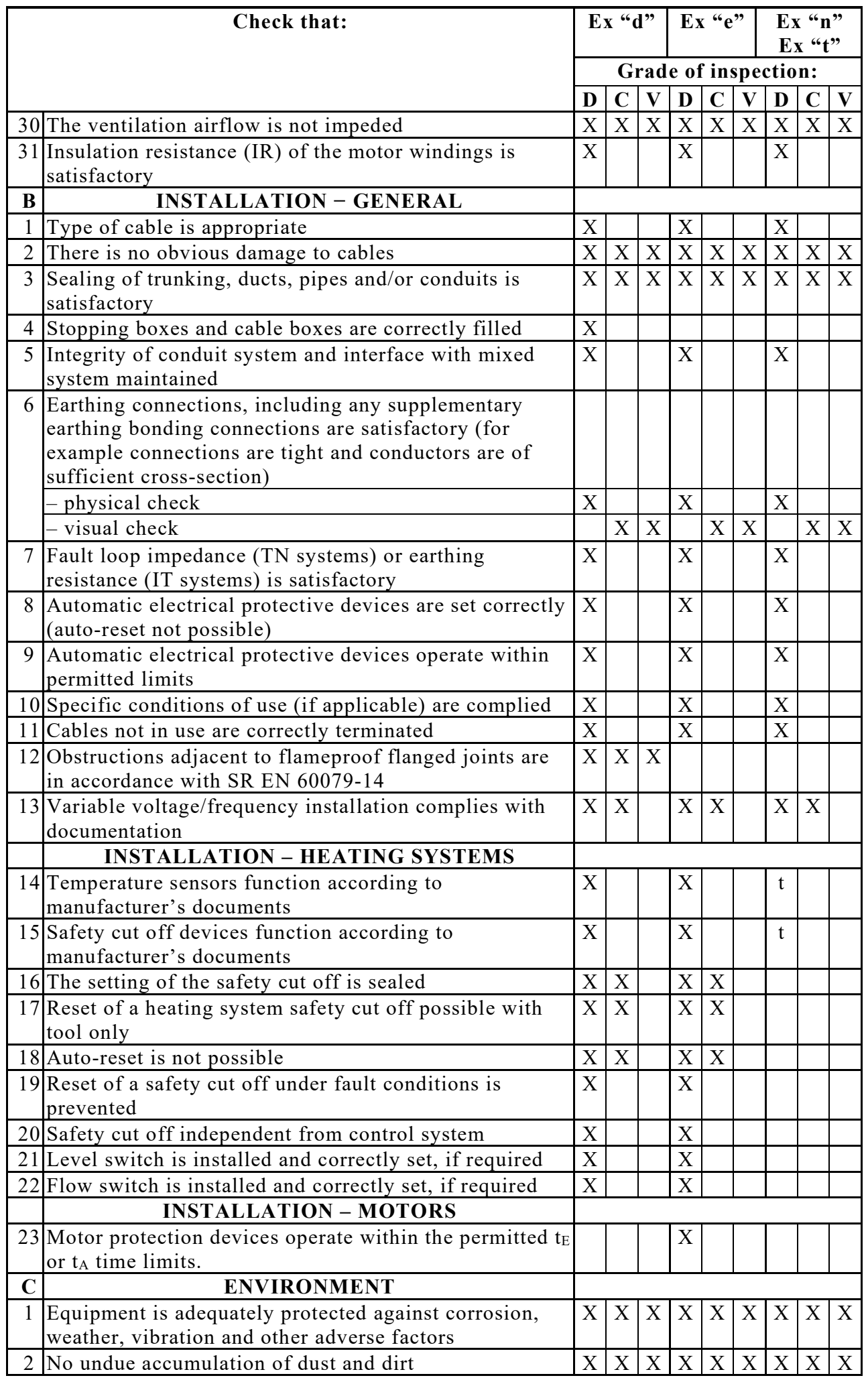




\begin{tabular}{|c|c|c|c|c|c|c|c|c|c|}
\hline \multirow[t]{3}{*}{ Check that: } & \multicolumn{3}{|c|}{$E x " d "$} & \multicolumn{3}{|c|}{ Ex "e" } & \multicolumn{3}{|c|}{$\begin{array}{l}\text { Ex "n" } \\
\text { Ex "t" }\end{array}$} \\
\hline & \multicolumn{9}{|c|}{ Grade of inspection: } \\
\hline & D & $\mathbf{C}$ & $\mathbf{V}$ & D & $\mathbf{C}$ & $\mathbf{V}$ & D & $\mathbf{C}$ & $\mathbf{V}$ \\
\hline \begin{tabular}{c|l}
3 & Electrical insulation is clean and dry
\end{tabular} & & & & $\mathrm{X}$ & & & $\mathrm{X}$ & & \\
\hline
\end{tabular}

After the erection of an installation, an inspection program, comprising periodical inspections must be elaborated.

When establishing the grade and time interval between periodic inspections for fixed installations and equipment some specific aspects shall be considered (the type of equipment, the manufacturer's guidance, the factors governing its deterioration, the area classification and/or the EPL requirements, the results of previous inspections; also, the experience of the personnel on similar installations and equipment can be used in determining the inspection strategy). The time interval between periodic inspections shall not exceed three years without consulting of an expert. Intervals between periodic inspections exceeding three years should be based on an assessment including relevant information [1, 4].

After establishing an inspection interval, the installation/equipment should be subjected to additional interim sample inspections to check that the inspection program (interval and grade of inspection) is adequate or has to be adjusted. When large numbers of similar items (items of same manufacturer, type and type of protection) such as electric motors, luminaires, junction boxes, etc. are installed (at the same time) in a similar environment, operating in the same conditions it may be feasible to carry out periodical inspections on a sample basis provided that the number of samples in addition to the inspection frequency is subjected to review. It is recommended that all items be subjected at least to a visual inspection [1].

Movable electrical equipment (hand-held, portable, and transportable) is particularly prone to damage or misuse. Therefore, the interval between periodic inspections may need to be reduced [1].

The time interval between periodic inspections must not exceed the following (without seeking expert documented advice) [1]:

a) hand-held and portable equipment shall be visually checked by the user, before each use, to ensure that the equipment is not obviously damaged;

b) all equipment shall be submitted to a close inspection at least every 12 months;

c) enclosures which are frequently opened (such as battery housings) shall be given a detailed inspection at least every 6 months.

Changing the inspection period after it has been established must be documented (the reason can be, for example, based on the results of previous inspections).

After any adjustment, maintenance, repair, reclamation, modification or replacement, the equipment (or relevant parts of equipment subjected to mentioned operations) shall be inspected according the relevant inspection operations considering also the type of protection [1].

Inspections require competent personnel. It is obvious that the personnel involved in specific inspection activities related to equipment/installations operating in potentially explosive atmospheres shall possess adequate and specific knowledge, skills and competencies [6]. The personnel performing inspections in Romania, according the requirements of normative NEx 01-06/2007, must be authorized by INSEMEX Petrosani considering also the provisions of applicable standards [7].

The personnel performing inspections must possess (in terms of competence, knowledge and skills), at least the following [1,7]:

a) have a knowledge of area classification/EPL and sufficient technical knowledge to understand its implications for the location under consideration; 
b) have technical knowledge and understanding of the theoretical and practical requirements for electrical equipment and installations used in those hazardous areas;

c) understand the requirements of visual, close and detailed inspections as they relate to the installed equipment and installations.

In order to record the results of inspections one of the possibilities, and the most used, is to fill-in an inspection sheet for each equipment operating in potentially explosive atmospheres. Of course, there are certain specific elements that an inspection sheet should possess in order to identify the equipment and correctly perform the inspection. These specific elements should be:

- nature of equipment (e.g. electric motor, luminaire, junction box etc.);

- manufacturer of equipment;

- type of equipment - given by the manufacturer and specified on equipment label;

- Ex marking showing the equipment group, category, type(s) of protection etc. (e.g. II2G Ex db eb IIC T4 Gb);

- classification of hazardous area in which the equipment is installed (e.g. zone 1);

- mounting position (in medium and large installations, where more equipment of the same type is installed is very important to know which equipment was found to have deficiencies related to the type(s) of protection involved in order to provide protection to explosion; that is because the maintenance team might be different from the inspection team and is important to identify fast the faulty equipment);

- type of inspection;

- grade of inspection;

- operations to be performed according the specific inspection and type(s) of protection of equipment (as presented in the specific standard);

- date of the inspection;

- the findings/results of the inspection;

- recommendations for maintenance/repairs and the next inspections;

- identification of the person that performed the inspection.

\section{Practical examples regarding possible findings during inspection of electrical equipment}

When performing inspections to ensure that the installations and equipment are maintained in a satisfactory condition for continued use within a hazardous area, is important to check all applicable items to the specific equipment (related to the grade and type of inspection and to the type(s) of protection).

Some practical examples of aspects that can be highlighted during inspections (and which can influence protection to explosion of an equipment) are presented in the examples bellow:

- Equipment not appropriate to zone requirements of the location (Figure 1 and 2)

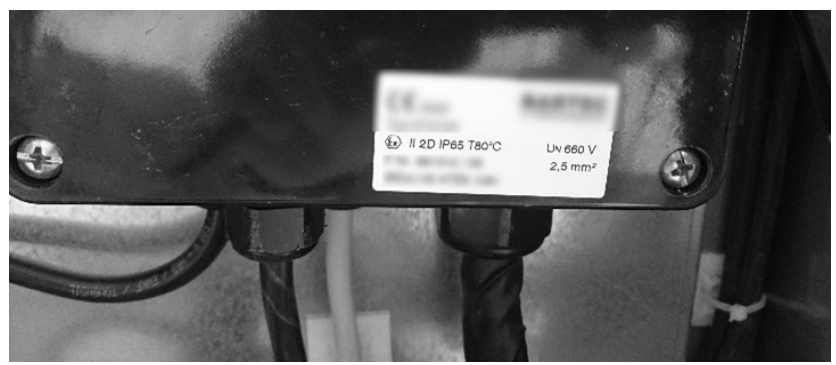

Fig. 1. Equipment installed in zone 2 (generated by flammable gas) but certified only for explosive atmospheres generated by combustible dusts 


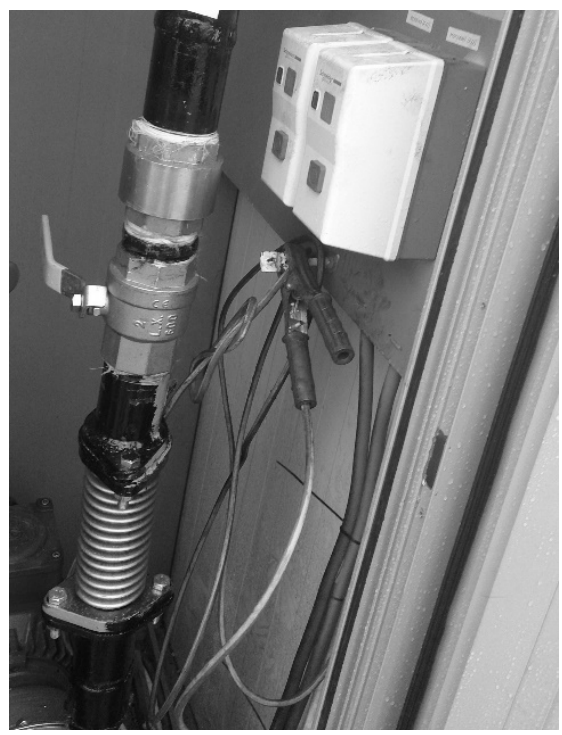

Fig. 2. Equipment in normal construction installed in hazardous area classified as zone 2

- $\quad$ Evidence of unauthorized modification (Figure 3)

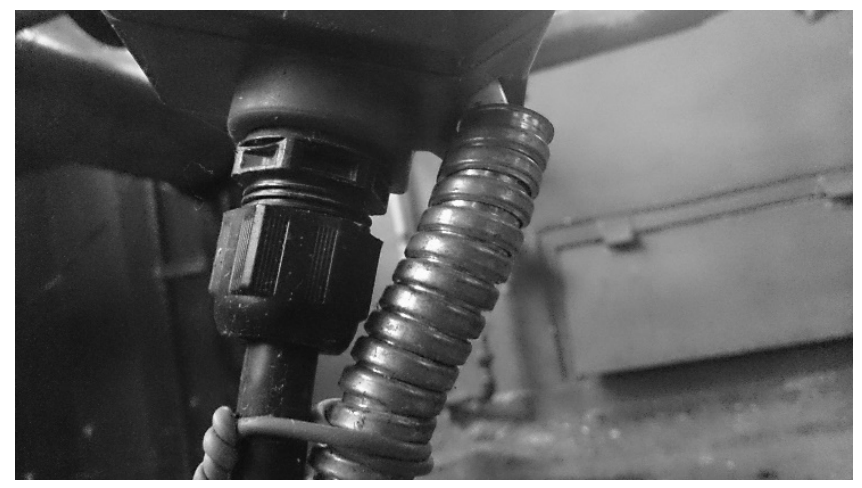

Fig. 3. Ex equipment installed in zone 2 but presenting an unauthorized modification (a hole not covered by the certificate was performed in equipment enclosure)

- Bolts are not complete (Figure 4)

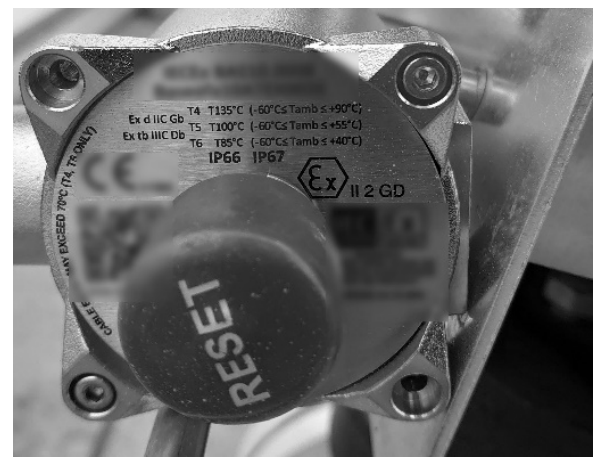

Fig. 4. Equipment not having all bolts 
- Cable entry devices and blanking elements are not of the correct type (Figure 5 and 6)

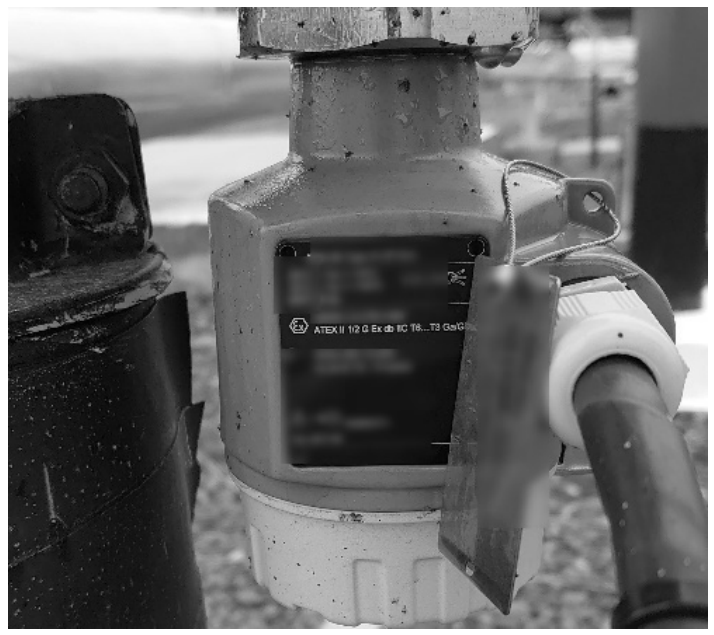

Fig. 5. Non-Ex cable gland installed to an Ex d equipment

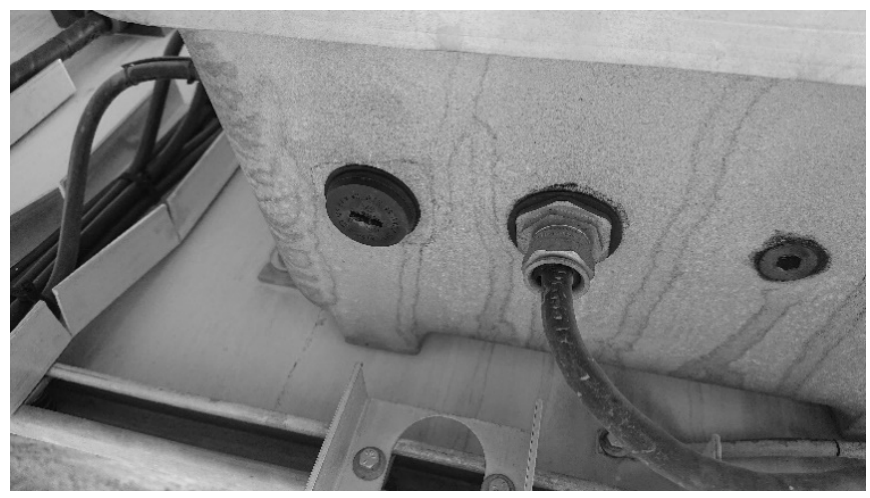

Fig. 6. Ex e blanking element installed to an Ex d equipment

\section{Conclusions}

In the paper were presented relevant aspects related to inspection of electrical equipment designed for use in potentially explosive atmospheres. The focus was on electrical equipment designed for use in potentially explosive atmospheres generated by flammable gas, vapours or mists having the types of protection flameproof enclosure "d" and increased safety "e"; but there are also a lot of common elements to other types of protection.

The first and second part of the paper presented some important aspects related to inspections: importance of performing inspections, classification of inspections, operations to be performed during inspections, factors influencing the inspection program, competence of personnel and the content of an inspection sheet.

In the third part of the paper were presented some examples of equipment with type of protection " $\mathrm{d}$ " and "e presenting deficiencies (frequent deficiencies).

All the presented aspects have a specific importance for the personnel involved in performing inspection and maintenance activities. 


\section{References}

1. Standard SR EN 60079-17 (2014)

2. Directive 2014/34/EU (2014)

3. L. Moldovan, S. Burian, G.A. Gaman, M. Paraian, M. Magyari, Proceedings of the 17th International Multidisciplinary Scientific Geoconference SGEM 2017 17, 531-538 (2017)

4. M. D. Rad, M. Magyari, L. Moldovan, D. Fotau, D. Salasan, Proceedings of the 20th International Multidisciplinary Scientific Geoconference SGEM 2020 20, 657-664 (2020)

5. Standard SR EN 60079-14 (2014)

6. L. Moldovan, M. Magyari, A. Andris, G. Pupazan, C. Moldovan, MATEC Web of Conferences 305, 00037 (2020)

7. Normative NEx 01-06 (2007)

8. D. Grecea, M. Darie, T. Csaszar, MATEC Web of Conferences 305, 00083 (2020)

9. V. M. Pasculescu, S. M. Radu, E. Ghicioi, D. Pasculescu, T. Niculescu, Proceedings of the 14th International Multidisciplinary Scientific Geoconference SGEM 20141 (2), $43-50$ (2014) 